\title{
REVIEW
}

\section{Role of human papilloma virus infection and oral-genital contact in oral cancer ethiopathogenesis}

\author{
Stanko $\mathrm{P}^{1}$, Kruzliak $\mathrm{P}^{2,3,4}$, Labas $\mathrm{P}^{5}$ \\ Department of Stomatology and Maxillofacial Surgery, Comenius University and St Elisabeth Hospital, \\ Bratislava, Slovakia. peter.stanko@ousa.sk
}

\begin{abstract}
Head and neck squamous cell carcinoma and especially oropharyngeal squamous cell carcinoma is a very significant cause of morbidity and mortality. The majors risk factors of these tumors are tobacco smoking, chewing and alcohol consumption. But there is a group, non-drinking and non-smoking, patients with oropharyngeal squamous cell carcinoma. In these patients may be oral-genital contact and human papillomavirus infection the major risk factor for oral carcinogenesis. Aim of this review is to point out this fact in correlation with clinical studies and clinical conclusion for medical practice (Fig. 1, Ref. 32). Full Text in PDF www.elis.sk. Key words: head and neck squamous cell carcinoma, oropharyngeal squamous cell carcinoma, human papilloma virus infection, oral-genital contact, ethiopathogenesis.
\end{abstract}

Head and neck squamous cell carcinoma (HNSCC) is a significant cause of morbidity and mortality around the world with more than 500,000 new cases worldwide and high rates notably in Southeast Asia and eastern Europe $(1,2)$. While the incidence of HNSCC has remained stable, the incidence of oropharyngeal squamous cell carcinoma (OSCC), a subset of HNSCC has increased 2 $\%$ to $3 \%$ annually among American men from 1973 to 2001 (1). The area which is termed the oropharynx includes the soft palate, base of tongue, tonsillar region, and posterior pharynx. Shiboski et al. found an increase in tongue and tonsil carcinoma in young adults (ages 20-39 yrs), five-fold among young men compared with a two-fold increase in older age groups (3). Much is known today about the risk factors which can lead to cancer, as well as its poor prognosis, yet oral cancer still remains an under diagnosed and often fatal disease. Tobacco smoking and chewing and alcohol consumption are the main risk factors for HNSCC and OSCC and have been estimated to account for the vast majority of the disease burden worldwide (4). However, there is a small population of nonsmoking and nondrinking patients with head and neck squamous cell carcinoma, so other risk factors may be important (5). Over the past 15 years, human papillomavirus (HPV), the necessary cause of cancer of the cervix (6), has also been etiologically linked with $\operatorname{HNSCCs}(2,7,8)$. It is estimated that up to

${ }^{1}$ Department of Stomatology and Maxillofacial Surgery, Comenius University and St Elisabeth Hospital, Bratislava, Slovakia, ${ }^{2}$ Department of Cardiovascular Diseases, International Clinical Research Center, St. Anne's University Hospital and Masaryk University, Brno, Czech Republic, ${ }^{3} \mathrm{Di}-$ vision of Cardiovascular Diseases, Mayo Clinic, Minnesota, Rochester, USA, ${ }^{4}$ Institute of Normal and Pathological Physiology, Slovak Academy of Sciences, Bratislava, Slovakia, and ${ }^{5}$ Department of Surgery, Comenius University and University Hospital, Bratislava, Slovakia

Address for correspondence: $\mathrm{P}$. Stanko, MD, PhD, Department of Stomatology and Maxillofacial Surgery, Comenius University in Bratislava and St Elisabeth Hospital, Heydukova 10, SK-812 50 Bratislava, Slovakia. Phone: +421.2.32249742, Fax: +421.2.32249724
15-20\% of all head and neck squamous cell carcinomas are associated with high-risk HPV infection 9-13). This prevalence varies broadly, depending on the sublocation of the tumor, the studied population, the detection method, and the type of specimen used (10-13). The highest rates of HPV-DNA (up to $70 \%$ ) have been found in oropharynx squamous cell carcinomas (OSCCs), especially the tonsils $(7,12,14-16)$. Our review is focused to point on the importance of papilloma virus and oral-genital contact in ethiopathogenesis of oral cancer.

\section{Oral carcinogenesis}

Oral cancer is characterized in general as a disease attributed to multiple exposures, with tobacco and alcohol abuse considered to be the major risk factors. Other lifestyle and environmental factors have been identified as important contributors in the progression of this disease such as viruses, diet, actinic radiation, and dental factors. Dental factors include poor oral hygiene, and defective dental restorations which repeatedly irritate the oral mucosa. These factors produce an initial insult to the genetic stability of the affected tissue and trigger a cascade of events. Genetic changes have been identified and studied to better identify the pathway to carcinogenesis.

The most frequently mutated gene in human oral cancer is the p53 tumor suppressor gene. P53 is a nuclear phosphoprotein which arrests the cell cycle when DNA damage occurs. The p53 acts as a recessive tumor suppressor gene whereas mutants can behave as dominant oncogenes. The mutagenic effect of smoking and alcohol can be seen in Figure 1.

When a person smokes or drinks for prolonged periods there is continued mucosal damage initially causing an increase in cell number, hyperplasia. Over time, the continued exposure to tobacco or alcohol produces a genetic insult and cells begin to divide at a higher rate, and in unusual patterns changing the maturation of the epithelium which becomes disturbed or dysplastic. Eventually 


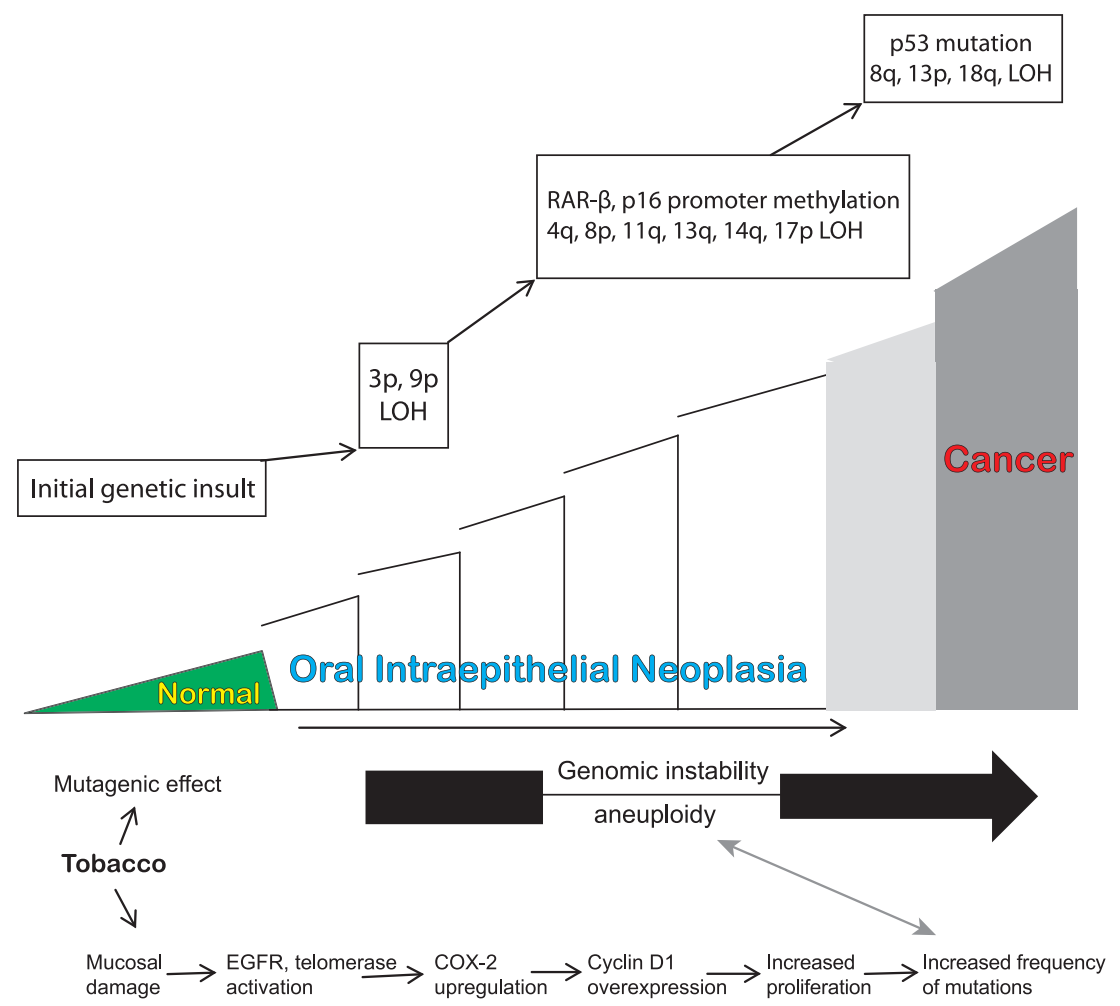

Fig. 1. Journal of Clinical Oncology, 2005.

the damaged mucosa cannot recover as p53 is mutated allowing unchecked cell division and the affected area progresses to cancer. It has also been shown that smokers and alcohol abusers who have had an oral cancer are at a higher risk of either a recurrence of the original cancer or having a new cancer in the field which was subjected to the offending carcinogen $(17,18)$. Approximately $75 \%$ of oral cancers can be attributed to smoking and/or alcohol abuse (18), but we know that not all smokers get cancer. It is not known why some smokers and drinkers are affected by their habit and others are not. Interestingly, approximately $25 \%$ of cancers occur in people with no known risks suggesting cofactors, such as viruses, as a possible etiology (19).

\section{Viruses associated with cancer}

The link between viruses and cancer was one of the pivotal discoveries in cancer research. Today, it is generally agreed that viruses are involved in 10-20\% of all cancers (20). Many viruses target the $\mathrm{p} 53$ and $\mathrm{pRb}$ tumor suppressor pathways, altering the cell cycle. Hepatitis B infection, for example, is associated with an increased risk of hepatocellular carcinoma development. Hepatitis B proteins, such as the Hepatitis Bx protein, regulate transcription of many candidate genes for liver carcinogenesis by trans-mechanisms. They also alter mechanisms of apoptosis and interfere with nucleotide excision repair of damaged DNA (21). This mechanism is similar to the pathogenesis of high-risk types of the human papillomavirus (HPV). HPV has been found to be associated with multiple types of epithelial cancers.

\section{Human papillomavirus and cancerogenesis}

HPV is a small DNA virus that infects the squamous epithelium of the skin or mucosa. It causes both asymptomatic infections and various benign or malignant lesions. Its structure consists of a non- enveloped, circular, double stranded DNA of about 8000 base pairs. The HPV genome consists of 9 open-reading frame sequences, located on only one of the strands of DNA, and is divided into seven early-phase genes (E) and two late-phase genes (L). About $10 \%$ of the genome is contained in the long control region (LCR) and functions in the regulation of viral gene expression. The remainder of the genome is organized into early (E) or late (L) genes, encoded by $50 \%$ and $40 \%$ of the genome, respectively.

There are approximately 100 types of HPV. The type is determined by a greater than $10 \%$ sequence difference in the E6, E7, and $\mathrm{L} 1$ regions. The L-late genes encode for proteins involved in viral spread, such as capsid proteins. The L1 and L2 genes encode the major and minor capsid proteins which are only expressed in terminally differentiated squamous epithelial cells. The E-early genes encode nonstructural proteins that regulate virus transcription and replication and are expressed in nonproductively infected cells and in transformed cells (22-24). HPV's have evolved proteins, specifically E6 and E7, to control the growth of the epithelial 
cells they infect. This was a necessity since these viruses require a metabolically active, dividing cell in order to complete their life cycle. The viral oncoproteins E6 and E7 from high-risk HPV types prevent cells from differentiating and

withdrawing from the cell cycle as they move outward through the cell layers, while those from low risk types do not (23). The E1 and E2 genes are responsible for initiation of DNA replication. E2 also regulates transcription through a feedback mechanism. When there are high levels of E6 and E7 the E2 gene will shut down viral transcription. The E2 gene normally binds to a sequence in the upstream regulatory region and monitors viral transcription by shutting down E6 and E7. In order for malignancy to occur after infection, the virus must become integrated in the host genome. When the virus integrates there is a break in the $\mathrm{E} 2$ region and the normal repressor activity of the virus is rendered ineffective and E6 and E7 are highly expressed. The E5 gene from high-risk viruses destabilizes the cell membranes and changes the cellular responses to programmed cell death or apoptosis and the E4 gene binds the cytoskeleton proteins and prevents a proper cellular differentiation. E6 binds to the tumor suppressor protein, p53 marking it for degradation, while E7 binds and inactivates retinoblastoma protein (pRB) (25).

\section{Oral-genital contact as a risk factor in oral cancer}

Oral-genital contact has been found epidemiologically to result in oral and cervical cancers within couples $(26,27)$. An analysis of the Swedish cancer registry data (1958-1996) showed that husbands of women with cervical cancer had a significantly increased risk of developing either tongue or tonsil cancer. Husbands of cervical cancer patients developed an excess (SIR over 2.00) of both tonsillar cancer (SIR 2.39 when wife with in-situ cancer and SIR 2.72 when wife with invasive cervical cancer) and cancer of the tongue. Also, women diagnosed with cervical carcinoma in-situ after the age of 50 were 2.58 times more likely to develop tonsillar cancer (26).

In a study by Herrero et al 1670 patients with oral cancer found that HPV16 was detected in most of the oropharyngeal cancers and the patients with tumors containing the HPV16 strain were three times more likely to report a history of oral sex than those with tumors that did not contain the virus (7). Specific sexual behaviors have been more strongly associated with risk of an HPV-positive tumor, including a history of performing oral sex and oral-anal contact according to Gillison (24).

\section{Human papilloma virus and oral carcinoma}

The first reports of HPV in oral cancers came in the early 1980 's. Since then many studies have looked at HPV and its possible connection to the development of oral cancer and more specifically oropharyngeal cancer (OSCC). The role that HPV may play in OSCC has been controversial. The controversy relates mainly to the variable detection rate of HPV in these tumors, but this is due to the different sensitivities of various detection techniques, the type of specimen taken and its handling, as well as the population examined as many tumors are unquestionably tobaccorelated. Also important was the sub-site examined. There appears to be different etiologies depending on the oral sites; for example lip cancer is undoubtedly related mainly to sun exposure (28). The human papillomavirus (HPV) DNA has been consistently detected in $20 \%$ of HNSCCs overall and in $50 \%$ of OSCCs. The following studies confirm this finding and support the hypothesis of HPV as an etiology in oral cancers.

An important pathway in many cancers is the methylation of regions of DNA important in the progression of the cell cycle and this is a marker that is being looked at in cancers studies. The term DNA methylation refers to the transfer of a methyl group to cytosine residues, which are stably maintained at $\mathrm{CpG}$ dinucleotides (meCpGs). Methylated CpGs lead to the binding of transcriptional repressors, part of a network of epigenetic regulatory pathways. Balderas-Loaeza et al reports hypermethylation of the $\mathrm{L} 1$ gene and part of the long control region, a diagnostically important segment of the viral DNA, in 10 out of $12 \mathrm{HPV}-16$ positive oral carcinomas from Mexican patients. These data indicate epigenetic changes of HPV-16 in oral carcinomas similar to those in anogenital carcinomas suggesting carcinogenic processes under the influence of HPV-16 in most if not all of these oral malignant lesions (29).

Study by Pintos et al matched on age and gender, examined oral exfoliated cells from the buccal mucosa utilizing consensus PCR as well as serum based ELISA. $30 \%$ of their cases were nonsmokers and $11 \%$ were non-drinkers. HPV DNA was detected in $19 \%$ of cases (14 out of 72 ), and $5 \%$ of controls (six out of 129 ). Among tonsilrelated cancers (palatine tonsil and base of tongue) viral DNA was detected in $43 \%$ of cases (30). Smith et al utilized oral exfoliated cells to look for HPV. They found that $22.9 \%$ (201 cases) and $10 \%$ (333 controls) of controls were HPV positive. They concluded that oral exfoliated cells were predictive of HPV types in tumor tissue (31). Dahlstrom et al designed the only study which compared smokers to non-smokers. They looked for the presence of HPV-16 antibodies in ever-smoker and never smoker patients matched on age ( \pm 5 years), sex, and tumor site. Serum was assayed for HPV-16 L1 virus-like particles by using an ELISA. They found HPV-16 antibodies in $40.8 \%$ cases and $9.2 \%$ controls. Subjects with HPV-16 seropositivity was more common in never-smokers with HNSCC than in ever-smokers (43.3\% vs 38.3 $\%$, respectively), this difference was not statistically significant. They only used subject's serum which has not been found to be as reliable a marker of HPV infection as the examination of tumor DNA and they did not look at alcohol as a confounding factor (32).

\section{Conclusion}

Specific sexual behaviors (oral sex, oral-anal contact) are frequently associated with high risk of human papilloma viruspositive oropharyngeal squamous cell carcinoma. Though clinical conclusion for the medical practise should be early detection of the HPV infection in these groups of population. Simultaneously the screening also rises public awareness. Preventive HPV vaccines may be effective in preventing cervical infection in women and may likewise prevent oral infection with subsequent oropharyngeal cancer. But modification of the sexual behavior, especially heterosexual or homosexual promiscuity, has be strongly recommended. 


\section{References}

1. Begum S, Cao D, Gillison M, Zahurak M, Westra Wh. Tissue Distribution of Human Papillomavirus 16 DNA Integration in Patients with Tonsillar Carcinoma. Clin Cancer Res 2005; 11: 5694-5699.

2. Franceschi S, Munoz N, Bosch XF, Snijders PJ, Walboomers JM. Human papillomavirus and cancers of the upper aerodigestive tract: a review of epidemiological and experimental evidence. Cancer Epidemiol Biomarkers Prev1996; 5: 567-575.

3. Shiboski Ch, Schmidt BI, Jordan Rc. Tongue and Tonsil Carcinoma: Increasing Trends in the U.S. Population Ages 20-44 Years. Cancer 2005; 103: 1843-1849.

4. Blot WJ, McLaughlin JK, Devesa SS, Fraumeni JF Jr. Cancers of the oral cavity and pharynx. In: Schottenfeld D, Fraumeni JF Jr, editors. Cancer epidemiology and prevention. New York: Oxford University Press; 1996. p. 666-680.

5. Farshadpour F, Hordijk GJ, Koole R, Slootweg PJ. Non-smoking and non-drinking patients with head and neck squamous cell carcinoma: a distinct population. Oral Dis 2000; 13: 239-243.

6. Walboomers JM, Jacobs MV, Manos MM et al. Human papillomavirus is a necessary cause of invasive cervical cancer worldwide. J Pathol 1999; 189: 12-19.

7. Herrero R, Castellsague X, Pawlita M et al. Human papillomavirus and oral cancer: the International Agency for Research on Cancer multicenter study. J Natl Cancer Inst 2003; 95: 1772-1783.

8. Smith EM, Ritchie JM, Summersgill KF et al. Age, sexual behavior and human papillomavirus infection in oral cavity and oropharyngeal cancers. Int J Cancer 2004; 108: 766-772.

9. D‘Souza G, Kreimer AR, Viscidi R et al. Case-control study of human papillomavirus and oropharyngeal cancer. New Engl J Med 2007; 356: 1944-1956.

10. Hafkamp HC, Manni JJ, Speel EJM. Role of human papillomavirus in the development of head and neck squamous cell carcinomas. Acta Oto-Laryngologica 2004; 124: 520-526.

11. Herrero R, Castellsague $X$, Pawlita $M$ et al. Human papillomavirus and oral cancer: the international agency for research on cancer multicenter study. J Nat Cancer Inst 2003; 95: 1772-1783.

12. Lindel K, Beer KT, Laissue J, Greiner RH, Aebersold DM. Human papillomavirus positive squamous cell carcinoma of the oropharynx: a radiosensitive subgroup of head and neck carcinoma. Cancer 2001; 92 : 805-813.

13. Strome SE, Savva A, Brissett AE et al. Squamous cell carcinoma of the tonsils: a molecular analysis of HPV associations. Clin Cancer Res 2002; 8: 1093-1100.

14. Fakhry C, Gillison ML. Clinical implications of human papillomavirus in head and neck cancers. J Clin Oncol 2006; 24: 2606-2611.

15. Klussmann JP, Weissenborn SJ, Wieland $\mathbf{U}$ et al. Prevalence, distribution, and viral load of human papillomavirus 16 DNA in tonsillar carcinomas. Cancer 2001; 92: 2875-2884.
16. Mork J, Lie AK, Glattre $\mathbf{E}$ et al. Human papillomavirus infection as a risk factor for squamous-cell carcinoma of the head and neck. New Engl J Med 2001; 344: 1125-1131.

17. Weinberger PM, Yu Z, Haffty BG et al. Molecular Classification Identifies a Subset Of Human Papillomavirus--Associated Oropharyngeal Cancers with Favorable Prognosis. J Clin Oncol 2006; 24: 736-747.

18. Blot WJ, Mclaughlin JK, Winn DM et al. Smoking And Drinking In Relation To Oral And Pharyngeal Cancer. Cancer Res 1988; 48: 3282-327.

19. Sciubba JJ. Oral Cancer. The Importance of Early Diagnosis and Treatment. Am J Clin Dermatol 2001; 2: 239-251.

20. Talbot SJ, Crawford DH. Viruses and Tumours--An Update. Eur J Cancer 2004; 40: 1998-2005.

21. Rabe C, Pilz T, Klostermann $\mathbf{C}$ et al. Clinical Characteristics And Outcome of a Cohort of 101 Patients with Hepatocellular Carcinoma. World J Gastroenterol 2001; 7: 208-215.

22. Heilman CA, Law MF, Israel MA, Howley PM. Cloning Of Human Papillomavirus Genomic DNAs and Analysis of Homologous Polynucleotide Sequences. J Virol 1980; 36: 395-407.

23. Baseman JG, Koutsky LA. The Epidemiology of Human Papillomavirus Infections. J Clin Virol 2005; 32 (Suppl 1): S16-24.

24. Gillison Ml. Human Papillomavirus-Associated Head and Neck Cancer is a Distinct Epidemiologic, Clinical, and Molecular Entity. Semin Oncol 2004; 31: 744-754.

25. Claudio PP, Howard CM, Baldi A et al. P130/pRB2 has Growth Suppressive Properties Similar to yet Distinctive from those of Retinoblastoma Family Members pRB and p107. Cancer Res 1994; 54: 5556-5560.

26. Hemminki K, Dong C. Cancer in Husbands of Cervical Cancer Patients. Epidemiology 2000; 11: 347-349.

27. Hemminki K, Jiang Y, Dong C. Second Primary Cancers After Anogenital, Skin, Oral, Esophageal and Rectal Cancers: Etiological Links? Int J Cancer 2001; 93: 294-298.

28. Scully C. Oral Cancer; the Evidence for Sexual Transmission. Br Dent J 2005; 199: 203-207.

29. Balderas-Loaeza A, Anaya-Saavedra G, Ramirez-Amador Va et al. Human Papillomavirus-16 DNA Methylation Patterns Support a Causal Association of the Virus with Oral Squamous Cell Carcinomas. Int J Cancer 2007; 120: 2165-2169.

30. Pintos J, Black Mj, Sadeghi N et al. Human Papillomavirus Infection and Oral Cancer: A Case-Control Study in Montreal, Canada. Oral Oncol 2007; 26.

31. Smith EM, Ritchie JM, Summersgill KF et al. Human Papillomavirus in Oral Exfoliated Cells and Risk of Head and Neck Cancer. J Natl Cancer Inst 2004; 17 (96): 449-455.

32. Dahlstrom KR, Adler-Storthz K, Etzel CJ et al. Human Papillomavirus Type 16 Infection and Squamous Cell Carcinoma of the Head and Neck in Never-Smokers: A Matched Pair Analysis. Clin Cancer Res 2003; 9: 2620-2626. 